\title{
O passado e a História Difícil para o ensino e aprendizagem da História
}

\author{
The past and the Burdening History for learning and teaching \\ History
}

\author{
Rita de Cássia Gonçalves ${ }^{1}$
}

\section{RESUMO}

Apresenta discussões relacionadas à forma como a ditadura civil militar enquanto conceito é apresentado tanto em documentos oficiais, como nas DCN's e livro didático e como este é abordado nas aulas de História da Educação Básica. O modo como o passado tem sido resgatado para a construção da aprendizagem é o objeto de análise do presente trabalho, que se utiliza de análise documental e de observação empírica. Apresenta um breve histórico do ensino de História do período entre as décadas de 1960 e 1980. Também discorre sobre os estudos recentes, sobre História Difícil dentro da perspectiva da Educação Histórica, indagando como este período está apresentado em alguns documentos oficiais que regem a estrutura curricular. Por fim, tece considerações sobre o ensino da História e como a aprendizagem histórica pode superar um tipo de pensamento maniqueísta, implantado durante os governos militares, que ainda se encontra presente, e necessita de espaço para que seja superado no ambiente escolar e abra possibilidade para a discussão e debates que possibilitem o desenvolvimento de argumentações sobre temas controversos. Fundamenta teoricamente suas análises em estudos de pesquisadores como Bodo von Borries (2011, 2016), Jörn Rüsen (2001, 2010, 2012) e Maria Auxiliadora Moreira dos Santos Schmidt (2006, 2009, 2011, 2013, 2015).

Palavras-chave: História Dificil. Educação Básica. Professores. Passado. Ditadura Civil Militar..

\section{ABSTRACT}

Presents discussions related to the military civil dictatorship as a concept as is presented both in official documents, as in the DCN's and textbook and as they are approached in the Basic History classes. The way the past has been rescued for the construction of learning is the object of work analysis, which it

1 Doutora em Educação. Professora do PPGE-UTP/PR. E-mail: professoraritadecassia@gmail.com; rita.goncalves@utp.br. 
uses documentary analysis and empirical observation. Presents a brief history of the teaching of History from the 1960s to the 1980s. It also discusses recent studies on Burdening History within the perspective of History Education, investigating how this period is presented in some official documents that govern the curricular structure. Finally, it ponders considerations about the teaching of history and how historical learning can overcome a Manichean type of thinking, deployed during the military administrations, which is still present, and needs space to be overcome in the school environment and open space for the discussion and debates that allow the development of arguments on controversial issues. Based on analysis theoretically on studies of researchers such as Bodo von Borries $(2011,206)$, Jörn Rüsen (2001, 2010, 2012) and Maria Auxiliadora Moreira dos Santos Schmidt (2006, 2009, 2011, 2013, 2015).

Keyword: Burdening History. Basic School. Teachers. Past. Civil Military Dictatorship.

\section{Introdução}

Como a História é uma ciência que se utiliza do passado para fazer as suas análises e discussões, muitos assuntos são trazidos à tona. Entre eles, alguns parecem levantar maiores polêmicas, como o caso da ditadura civil militar brasileira. Questões do passado recente relacionadas a este período, sobre tortura e repressão no ensino e aprendizagem de História na escola se tornam cada vez mais um desafio para professores no Brasil. Sobre esse período histórico é possível fazer uma análise a partir daquilo que o historiador alemão Bodo von Borries (2011) conceitua como Burdening History e Maria Auxiliadora Schmidt (2015, p. 19) denomina História Difícil, termo que será usado neste texto.

A História recente do Brasil, marcada pela existência da ditadura civil militar entre os anos de 1964 e 1985, foi determinante para que a sociedade se desenvolvesse em torno de novas perspectivas e ideologias. Como um período marcado pela censura e pela ausência de liberdades democráticas, foram acentuadas as pressões econômicas e político-ideológicas, o que pode ser observado na forma de pensar o ensino de História. Após 1964, este foi tomado como alvo pelo poder político dominante, que procurou adequá-lo às suas necessidades de afirmação.

O estudo da História é sobretudo o estudo de partes do passado e embora pareça ser óbvia a sua utilização em contexto de escolarização, é importante refletir sobre a forma como essa temporalidade é entendida e abordada durante as aulas de História da Educação Básica. Ao lidar com o passado é comum perceber que os estudantes são orientados a pensar como se os acontecimentos históricos não tivessem relação com o seu presente. De acordo com Chaves (2006, p. 13), a História é sempre uma interpretação do presente, pois o nosso 
interesse no passado é contextualizar e compreender o presente através dos vestígios e relatos do passado.

Esses vestígios do passado podem ser encontrados nos mais diversos espaços. Sob a nomenclatura do "vintage", o passado tem sido resgatado e utilizado de diferentes formas: na moda, em artigos de decoração, na produção de livros e filmes. A mídia também se serve dele como forma de entretenimento, o que proporciona a crianças e jovens um contato com narrativas sobre os mais diversos episódios da História. Assim, é inegável que os estudantes da Educação Básica, de uma forma ou de outra, tenham conhecimento sobre vários conteúdos históricos abordados em sala de aula.

É correto afirmar que é no espaço escolar, sobretudo nas aulas de História, que esse contato com os acontecimentos do passado ganha um maior grau de orientação e de cientificidade. No entanto, os manuais didáticos muitas vezes se apresentam como detentores das informações sobre essa temporalidade, nos quais os acontecimentos históricos são apresentados de forma estanque e não problematizada. Os mais diversos episódios do passado, em alguns casos, são apresentados como verdades absolutas, em outros não fazem sentido para a práxis dos jovens em idade de escolarização, mas também existem materiais didáticos que procuram, através do uso de fontes, problematizar o passado, através das discussões que o tempo presente proporciona, lembrando que o processo de sua produção envolve uma complexidade que deve ser levada em conta para a análise. No entanto, como afirma Santos,

Se o professor tiver clareza dos aspectos que considera significantes sobre o passado, este entendimento pode servir de auxílio para desenvolver metodologicamente um trabalho que considere as ideias prévias do aluno e possibilitem a construção do seu conhecimento histórico. (SANTOS, 2013, p. 49).

Desse modo, este artigo apresenta discussões relacionadas à forma como os conceitos sobre a ditadura civil militar brasileira são apresentados tanto em documentos oficiais, como as DCN's e livro didático como são abordados nas aulas de História da Educação Básica tendo, como objeto de análise o modo como o passado tem sido resgatado para a construção da aprendizagem. Procura refletir sobre as formas pelas quais estudantes e professores estão buscando fontes para construir as narrativas sobre este período histórico temporalmente tão próximo, mas da mesma forma tão distante da compreensão dos jovens em idade de escolarização, assim como de boa parcela da sociedade brasileira. 
Considerando como esse período da História brasileira tem sido tratado, sem que esteja ocorrendo reflexões profundas sobre os acontecimentos marcantes do período, como as investigações e punições sobre os abusos cometidos, o papel dos vários sujeitos sociais que atuaram no período e como a ditadura civil militar brasileira tem sido tradada pela área jurídica e midiática, este período pode ser considerado como "desconfortável" como afirma o historiador Bodo Von Borries (2016) e ainda não foi enfrentado de modo franco pela sociedade brasileira e muito menos pela cultura escolar.

Embora esteja no rol dos conteúdos da disciplina de História, tanto do Ensino Fundamental quanto do Ensino Médio, ainda não se estabeleceu um amplo debate que proporcionasse o resgate de fontes diversas para auxiliar aos estudantes a construção de narrativas que auxiliem ao desenvolvimento da consciência histórica sobre a ditadura civil militar brasileira. Rüsen (2001) desenvolve uma tipologia que a classifica em quatro categorias: tradicional, exemplar, crítica e genética. As discussões sobre o ensino e aprendizagem de História têm procurado compreender como a disciplina História pode modificar as narrativas e desenvolver consciências históricas mais elaboradas, estudos dentro da perspectiva da educação histórica têm sido desenvolvidos como Castex (2008), Oliveira (2016).

Este texto está dividido em três momentos. O primeiro apresenta um breve histórico do ensino de História do período entre meados das décadas de 1960 e 1980, período em que teve vigência a ditadura civil militar brasileira. A seguir discorre sobre os estudos recentes, acerca da História Difícil dentro da perspectiva da Educação Histórica, indagando como este período está apresentado em alguns documentos oficiais que regem a estrutura curricular e em quais lugares e fontes do passado os estudantes buscam construir suas narrativas e conceitos sobre este período histórico. Por fim, tece considerações sobre o ensino da História e como a aprendizagem histórica pode superar um tipo de pensamento maniqueísta, implantado durante os governos militares, que ainda se encontra presente, e necessita de espaço para que seja superado no ambiente escolar e abra possibilidades para a discussão e debates que mostrem não apenas narrativas sobre o passado sem contradições e possibilitem o desenvolvimento de argumentações sobre temas controversos.

É necessário que novas abordagens sobre esse período propiciem a construção de narrativas que sejam resultado de interrogações acerca do passado que está no presente de uma forma crítica para auxiliar na construção de uma perspectiva de futuro que leve em conta o caráter humanista da ciência histórica. 


\section{Breve Discussão sobre o Ensino de História após a década de 1960}

No campo da educação e, mais especificamente, no que se refere ao ensino de História, o período militar trouxe grandes alterações, muitas das quais ainda não foram devidamente repensadas ou reordenadas. Uma nova concepção de educação, que buscava promover o controle dos cidadãos e formação para a vida integrada na sociedade, necessitava que a formação de professores, por exemplo, fosse adequada a essa nova perspectiva. Com o Decreto Lei $\mathrm{N}^{\circ}$. 547, de 18 de abril de 1969, houve a instalação das chamadas licenciaturas curtas, com a formação de professores em cursos rápidos. Segundo Neves (2014, p. 24) “inicialmente, a curta duração, no caso das licenciaturas, era de três anos, mas em 1972, pela Resolução $N^{\circ} .8$ do Conselho Federal de Educação, foi reduzida para um ano e meio, com um total de 1.200 horas".

No caso do ensino de História, os cursos superiores passaram a dar espaço para os Estudos Sociais, curso de licenciatura curta que tinha, em seu currículo, as disciplinas de História, Geografia, Ciências Sociais, Filosofia, Ciência Política, OSPB (Organização Social e Política do Brasil). Os Estudos Sociais também ofereciam as disciplinas obrigatórias para todos os cursos: EPB (Estudos dos Problemas Brasileiros), Educação Física e as disciplinas da área pedagógica. Com a promulgação da nova Lei de Diretrizes e Bases da Educação, a Lei 5.692 de 11 de agosto de 1971, o $1^{\circ}$ grau deveria ter, obrigatoriamente, um núcleo comum e uma parte diversificada. O núcleo comum era composto de Comunicação e Expressão, Estudos Sociais e Ciências, além de Educação Moral e Cívica (obrigatória já desde 1969), Educação Artística, Educação Física, Programa de Saúde e de Ensino Religioso. As disciplinas de História e Geografia, completamente descaracterizadas em sua epistemologia, passam a incorporar uma nova "matéria", denominada de Estudos Sociais. Quanto ao $2^{\circ} \mathrm{Grau}$, as disciplinas de História e de Geografia continuavam existindo, porém com a quantidade de aulas e abordagens diminuídas em relação às disciplinas consideradas como de formação especial.

Os objetivos do ensino dessas disciplinas estavam voltados para um modelo educacional propagandístico e cívico. Essa Lei estabeleceu as diretrizes e bases para o ensino de primeiro e segundo graus, conforme a nova terminologia para os antigos cursos primário, ginasial e colegial.

Introduziu-se nos Estudos Sociais um terceiro ingrediente representado pela Organização Social e Política do Brasil. Vinculandose diretamente a um dos três objetivos do $1^{\circ}$ e $2^{\circ}$ graus - o preparo ao 


\begin{abstract}
"exercício consciente da cidadania" - para a OSPB e para o Civismo devem convergir, em maior ou menor escala, não apenas a Geografia e a História como todas as demais matérias, com vistas a uma efetiva tomada de consciência da Cultura Brasileira, nas suas manifestações mais dinâmicas, e do processo em marcha do desenvolvimento nacional. (CHAGAS, 1993. p. 403)
\end{abstract}

Como afirma Trindade (2014, p. 44) "o Estado, em suas várias instâncias, assume pleno controle dos conteúdos e de sua preparação”. Os conteúdos abordados pelos Estudos Sociais eram generalizados, sem haver nenhuma especificidade com relação ao objeto do conhecimento histórico. A preocupação dos Estudos Sociais estava intrinsicamente relacionada com a localização e interpretação de dados, sem uma perspectiva específica da epistemologia da História. O professor de Estudos Sociais, a partir desse momento, teria que dar aulas de História, Geografia, Organização Social e Política Brasileira (OSPB) e Educação Moral e Cívica (EMC), fosse ele historiador, geógrafo ou de outra formação na área das Ciências Humanas, como Sociologia, Filosofia ou mesmo Estudos Sociais.

Com a redemocratização no Brasil, na década de 1980, as discussões sobre o retorno da disciplina de História aos currículos escolares se tornaram recorrentes, sobretudo com relação à forma como esta seria tratada pela cultura escolar. Além disso, discutia-se a necessidade de se repensar o que e como ensinar o conhecimento histórico escolarizado, o que promoveu um processo de reformulação curricular que, nos estados da região sul e sudeste do país apresentou discussões e novas propostas inovadoras para o ensino de História que se tornaram referências para mudanças curriculares muitos estados do Brasil.

A educação e a sistematização do conhecimento estão sob responsabilidade do Estado. Com a instauração do Regime Militar, um ajuste foi feito nas Leis de Diretrizes e Bases atendendo a ideologia desenvolvimentista adotada pelo governo, como já foi afirmado anteriormente. Para atender às demandas do ensino primário e médio foi necessária uma nova reforma, instituída pela lei 5.692/71, que alterou a sua denominação para ensino de $1^{\circ} \mathrm{e}$ $2^{\circ}$ graus. Com a abertura política pela qual passava o país após o término da Ditadura Militar, foi discutida e elaborada uma nova Constituição brasileira, promulgada em 1988 e que ficou conhecida como Constituição Cidadã (BRASIL, 1988) por garantir direitos fundamentais a todo cidadão brasileiro, como a educação.

A nova versão da LDB, a Lei 9394/96 (BRASIL, 2002), discutida a partir da publicação da nova legislação, teve também o objetivo de pensar um Estado que não apenas se preocupasse, mas privilegiasse a educação, tornando o seu acesso e a permanência na escola, ao longo dos anos, cada vez maior e oferecesse a possiblidade a quem não teve em idade apropriada, garantindo efetivo cumprimento deste direito a todos os brasileiros. Além de 
estabelecer critérios como o calendário escolar com 200 dias letivos, a atual LDB acrescentou nova perspectiva acerca da profissionalização do Magistério. Esse documento passa a utilizar o conceito "profissionais da educação" o qual, por sua vez, veio a orientar as diretrizes e reformas educacionais posteriores.

Foi também, nesse mesmo período de resgate da disciplina, que se passou a discutir o papel dos professores no processo de reabertura política e de reorganização da disciplina de História. Como afirma Selva Guimarães Fonseca,

A imagem do ensino de história dos anos 80 - expressa por estas propostas curriculares e pelas experiências que as embasaram e seus desdobramentos - revela não uma 'década perdida', como os economistas têm dito sobre a economia brasileira nestes anos, mas uma década de tensões e criatividade. (FONSECA, 1995, p. 109).

No estado do Paraná, em 1990 foi publicada uma nova proposta curricular. O Currículo Básico para a Escola Pública do Estado do Paraná buscava a valorização das ações dos sujeitos, apontando como ocorriam as mudanças em relação às estruturas que demarcam o processo histórico das sociedades. Na esteira da abertura política brasileira, o Estado do Paraná implantava o Ciclo Básico de Alfabetização. Tal proposta de fundamentava numa concepção de alfabetização em que haveria, obrigatoriamente, a aprovação automática dos estudantes da primeira para a segunda série.

Essa concepção de alfabetização assume na escolarização um papel fundamental, pois, ao instrumentalizar o aluno para sua inserção na cultura letrada, cria as condições de operação mental capaz de apreensão de conceitos mais elaborados e complexos que vem resultando no desenvolvimento de formas sociais de produção (PARANÁ, 1990, p. 13).

No caso específico da disciplina de História, os conteúdos foram organizados de forma que, desde a $5 .^{\mathrm{a}}$ série, os estudantes pudessem compreender como era estruturado o conhecimento histórico, assim mantendo contato com a epistemologia da História. A utilização das fontes Histórias, trazida para dentro da sala de aula, se pautava numa relação 
mais estreita com a produção do conhecimento histórico e com a possibilidade de reconhecimento da existência de diferentes temporalidades.

Cabe destacar que esse documento buscou construir uma narrativa baseada numa concepção que superasse a dicotomia entre a História de vencedores e vencidos para trabalhar dentro de uma proposta de relação entre os diversos sujeitos. Portanto, ao contrário da narrativa tradicional, utilizada durante o período militar, a proposta de ensino de História apresentada pelo novo currículo buscava encontrar um ponto de ligação entre as duas Histórias.

Apesar de críticas com relação a algumas contradições no que se refere à escolha e articulação dos conteúdos, esse currículo foi um documento extremamente inovador acerca do ensino da disciplina de História naquele contexto.

Tanto no estado do Paraná quanto em outros estados, como Minas Gerais e São Paulo, que desenvolveram propostas curriculares consideradas inovadoras nos anos 1980 e 1990, a finalidade do ensino de História era enfatizar o aluno como produtor e não somente como sujeito passivo

que apenas observa a história já determinada nos programas e livros didáticos, estes recheados de atos heroicos de indivíduos das classes dirigentes da sociedade brasileira, que possibilitavam pouca relação com as experiências vivida pelos estudantes. (GERMINARI, GONÇALVES, 2016, p. 59).

As ideias inovadoras, colocadas pelas propostas curriculares de História das últimas décadas do século XX, contribuíram para transformação da formação de professores de História. Mas o modelo de formação para a graduação estava estruturado de forma dual, sendo que ainda existiam licenciaturas curtas e plenas, resquícios do período militar, a separação em conhecimentos específicos da disciplina e conhecimento pedagógico, reforçava a dicotomia entre pesquisa/ensino e conhecimentos teórico/prático. Esse modelo de formação docente

traduzido e generalizado entre nós pela fórmula 'três + um', marcou profundamente a organização dos programas de formação de professores de história. Durante três anos os alunos cursam as disciplinas encarregadas de transmitir os conhecimentos de história, 
em seguida cursam as disciplinas obrigatórias da área pedagógica e aplicam os conhecimentos na prática de ensino, também obrigatória (FONSECA, 2003, p. 62).

O Ensino de História, desde o início do século XXI, apresenta desafios tanto em aspectos relacionados à formação de professores quanto ao aporte teórico metodológico para os processos de ensino-aprendizagem. Diferente da pesquisa sobre o desenvolvimento cognitivo da aprendizagem referenciada na Psicologia da Educação, pesquisas recentes no campo do ensino de História apontam que o processo de ensino-aprendizagem histórica significativo depende de, entre outros fatores, uma relação intrínseca entre teoria e prática, conhecimento epistemológico e metodológico referenciadas na ciência histórica.

Pesquisas desenvolvidas em países como Inglaterra, Estados Unidos, Canadá, Portugal e Brasil buscam compreender o processo de ensino-aprendizagem histórica com o objetivo de orientar as intervenções didáticas tendo como referência a própria epistemologia da História, daí a denominação cognição histórica situada. Para as pesquisadoras Cainelli e Schmidt (2011)

a pesquisa em Educação Histórica pressupõe uma reflexão sobre a natureza do conhecimento histórico, tendo como objetivo apurar quais os sentidos que os indivíduos atribuem à História. Trata-se de uma área de investigação cujo foco está centrado, principalmente, nas questões relacionadas à cognição e metacognição histórica, tendo como fundamento principal a própria epistemologia da História. Assim, entre as investigações realizadas no âmbito da Educação História, encontram-se estudos sobre aprendizagem histórica, consciência histórica, ideias substantivas e ideias de segunda ordem em História e sobre narrativas (CAINELLI, SCHMIDT, 2011, p. 11).

Nesta direção, desde 2003, na Universidade Federal do Paraná, no Laboratório de Pesquisa em Educação Histórica tem se desenvolvido pesquisas que partem dos pressupostos da compreensão das ideias histórias dos sujeitos em contexto de escolarização, a investigação em cognição histórica situada.

O desenvolvimento das ideias históricas partindo dos pressupostos da aprendizagem histórica referem-se ao conjunto de competências de interpretar e compreender 
historicamente o mundo, a partir da noção que Peter Lee (2006) denomina literacia histórica. Ser historicamente competente envolve desenvolver alguns saberes como:

a) saber ler diferentes fontes históricas, com suportes diversos (fotografia, pinturas, documentos escritos, depoimentos orais, cultura material);

b) saber selecionar fontes para confirmação ou refutação de hipóteses;

c) saber entender o nós (identidade) e os outros (alteridade), em diferentes tempos e espaços;

d) saber levantar novas hipóteses de investigação;

Um dos objetivos do ensino de História é o desenvolvimento da capacidade inerente aos seres humanos de orientação no tempo, que é o que Jörn Rüsen (2001, 2007a, 2007b, 2010) chama de consciência histórica. Para este autor (RÜSEN, 2007b, p. 91) o aprendizado da História transforma a consciência histórica de orientação temporal em tema da didática da História. E, desse modo, a consciência histórica pode ser considerada como "a realidade a partir da qual se pode entender o que a História é, como ciência, e porque ela é necessária" (RÜSEN, 2001, p. 56-57).

\section{As discussões sobre Ensino de História no século XXI e a História Dificil}

Segundo Bodo von Borries (2016) o problema do ensino de História na época atual está centrado em uma maneira de construir competências de pensar historicamente diferentes contextos. Assim, "a "História" tem sido distinguida do "passado". O passado não pode ser restaurado ou reconhecido, mas somente ser reconstruído e contado; portanto, como já dito, uma "narrativa" estruturada é uma inevitável condição da História". (BORRIES, 2016, p. 175).

Uma aprendizagem histórica significativa passa pelo entendimento das formas como o passado está sendo reconstruído e contado por alunos e professores e como esta reconstrução está sendo estruturada. Que fatos passados estão construindo esta estrutura, os fatos passados estão sendo discutidos no ambiente escolar de acordo com o método histórico, ou o conhecimento escolar está sendo substituído em detrimento a fatos apresentados, significados e trazidos de fora do ambiente escolar para construir narrativas sobre o período da ditadura, sobre torturas e repressão e sobre o papel dos sujeitos que viveram e participaram ativamente de atos durante este período? 
As questões com que a educação brasileira em geral, e o ensino e aprendizagem da História no ambiente escolar mais especificamente, têm se confrontado como as questões do mundo virtual na escola, as discussões e debates sobre legislação como a implantação da nova Base Nacional Comum Curricular, a interferência de projetos como os da Escola Sem Partido mostram que o período histórico entre 1964 e 1985 precisa ser discutido na escola, e é imperioso que faça parte das discussões e dos documentos curriculares para que a aprendizagem histórica seja um processo crítico em que os sujeitos escolares compreendam este período como um momento em que a sociedade brasileira necessita um olhar de enfrentamento verdadeiro para o passado que é difícil e necessário.

Este período já está presente em livros didáticos, em planejamentos e legislações, mas necessita que o seu entendimento seja teórica e metodologicamente trabalhado com alunos para que a aprendizagem seja significativa, entendendo que aprender História é um processo cognitivo que também "envolve emoções e julgamentos morais" (SCHMIDT, 2015, p. 16-17).

Para Bodo von Borries,

Para as jovens gerações em sociedades que têm continuidade com períodos de grandes crimes, isso não implica simplesmente internalizar a história contada por avós, pais, autoridades e o estado. Em vez disso, eles têm que refletir, estudar, comparar, analisar e decidir por si mesmos quando lidam com interpretações históricas e a sua própria orientação. (VON BORRIES, 2016, p. 35).

No ambiente escolar, o aluno tem que aprender a elaborar narrativas, mas também a selecionar fontes e as evidências sobre o passado, analisar as mais plausíveis e as colocar em perspectiva a partir da discussão e do debate com as facetas do passado a que ele está exposto. Sendo assim, de acordo com Von Borries (2016), narratividade, seletividade e perspectividade talvez sejam as mais importantes características da História e têm que ser discutidas mais diligentemente. $\mathrm{E}$ o aluno tem que ter clareza que não é possível resgatar todo o passado, pois o seu resgate é seletivo. Seletividade não é fraqueza ou deficiência, mas uma situação estrutural do ser humano, viver é relembrar, como também é esquecer. Isso vale para o indivíduo, a família, a comunidade.

Estudar todo o passado é impossível e a significância é o critério valorizado através do qual o historiador avalia que partes do passado podem se encaixar em uma narrativa significativa e coerente que valha a pena ser selecionada para ser contada. Esta seleção 
ocorre entre pesquisadores, professores de História e representantes históricos da cultura popular e cada grupo faz a seleção por razões próprias, pois os historiadores não são os únicos a selecionar e estruturar o conhecimento histórico, que é construído também desde livros didáticos a programas de televisão. (SANTOS, 2013, p, 56).

Peter Seixas (1998) alerta também para o fato de que os jovens são apresentados a questões históricas e aos relatos sobre o passado muito antes das suas primeiras experiências escolares formais, e desenvolvem ideias sobre o passado por meio de suas próprias experiências. Também é possível afirmar que durante a vida escolar, os estudantes têm contato com outras versões sobre o passado, muitas vezes conflitantes com as presentes nos livros, nos documentos e discursos dos sujeitos escolares. Entretanto, durante muito tempo a cultura escolar partiu do princípio de que os estudantes não tinham ideias prévias sobre o passado nem experiências anteriores com questões que os auxiliassem a definir o significado do passado.

Rüsen (2001, p. 162-163) afirma que "o homem faz um determinado uso da História, toma decisões que têm subjacente uma interpretação do passado histórico a que atribui um determinado sentido e que orientam a sua ação". Ele classifica quatro tipos de orientação para a ação: a "consciência tradicional", que se orienta pelo 'passado dourado'; a "consciência exemplar", pela qual o passado é fornecedor de lições e exemplos; a "consciência crítica", que nega as orientações do passado, desconstruindo a História e a "consciência genética", pela qual a compreensão do passado serve para problematizar o presente e o futuro.

Tradicionalmente o ensino de História se apoia na ideia da importância de aprender o conteúdo da História e o professor considerado "competente" é aquele que identifica os acontecimentos no passado, muitas vezes somente por meio do livro didático, organiza seu discurso partindo dessa identificação e depois os apresenta para os alunos de maneira tradicional, crítica ou exemplar, de acordo com a terminologia utilizada por Jörn Rüsen (2001).

Essa didatização do passado através da apresentação de conteúdos históricos através de "explicações, comparações, interpretações" (SCHMIDT, 2011) convencionou-se chamar saber escolar.

Peter Seixas (1998, p. 777) afirma que "a História é a disciplina através da qual organizamos os vestígios e relatos do passado de uma forma significativa para nós no presente".

É possível afirmar que quando os relatos do passado são organizados, estabelecendo um contraponto ao que Jörn Rüsen (2001) denomina de carência de orientação, quando uma narrativa é construída, vestígios do passado que estão no presente são utilizados para responder a uma carência de orientação para a vida prática. Ao se voltar para o passado, o 
sujeito busca resolver questões postas pelo seu presente com vistas a projetar uma expectativa de futuro em uma atividade de compreensão que liga presente, passado e futuro respondendo as suas necessidades de compreensão histórica. (SANTOS, 2013, p. 63)

Os professores de História, por excelência, trabalham com o passado enquanto conceito. Seixas (2000) afirma que a tarefa de ensinar História, numa relação direta com uma temporalidade muitas vezes tão distante, o que para os professores significa, também, lidar com interpretações muitas vezes conflitantes. Essas interpretações sobre o passado se refletem a partir de três orientações que se diferenciam para a didática e para a epistemologia da História: A primeira orientação apresentada pelo autor foi chamada de 'reforço da memória coletiva" e consiste em simplesmente ensinar a melhor versão da História, ou seja, é necessário a invocação da melhor versão da História para mobilizar qualquer finalidade social ou nacional. Na segunda orientação, de cunho mais epistemológico, os estudantes são apresentados a duas versões sobre o mesmo fato e aprendem os critérios da disciplina para decidir o que torna a História válida. Finalmente, na terceira orientação, chamada de abordagem pós-moderna, ela reflete a incerteza sobre a noção de uma História melhor e os alunos têm a tarefa de compreender como os grupos diferentes organizam o passado histórico e como suas estratégias retóricas e narrativas servem aos propósitos do presente.

A primeira e a segunda orientação apresentadas neste trabalho de Seixas trazem alguns problemas, seja porque apresenta a História como utilitarista e dogmática ou como versões a serem defendidas sem reflexões. Desta maneira, não há necessidade assim de investigação e muito menos de debate e os alunos só necessitam aceitar ou defender um conhecimento já pronto e acabado. Já a terceira desenvolve a ideia que

[...] Narrativas históricas são organizadas como narrativas, com começo, meio e fim, com um significado expresso através da linguagem que está de acordo com suas próprias regras. O passado, por outro lado, não é organizado totalmente; não tem começo, meio ou fim (exceto o escolhido pelo historiador), nem tem significado (exceto o imposto pelo historiador) e existe além das regras linguísticas. (SEIXAS, 2000, p. 27).

De acordo com as três orientações apresentadas por Seixas nos parágrafos anteriores, os processos de ensino-aprendizagem histórica auxiliam ou não que o resgate do passado possibilite a construção de narrativas diversas sobre como o aluno compreende o período da ditadura civil militar e resgata aspectos sobre o passado para construir blocos de significados para os fatos a que eles têm acesso. 
Além disso, a História escolarizada apresenta, como uma de suas características, na relação entre passado e presente, versões que buscam apontar progresso ou declínio, o que impede o debate e a construção de narrativas que se utilizem de fontes diversas além dos documentos oficiais.

Seixas, assim como outros historiadores da Educação Histórica, afirma que os jovens aprendem sobre o passado constantemente e a partir de diferentes fontes. O cinema, a televisão e diversos outros recursos midiáticos apresentam uma infinidade de versões sobre o passado, muitas das quais não são mencionadas nas aulas de História ou mesmo nos livros-didáticos. E os alunos atribuem significância ao passado, a partir de suas experiências pessoais e do conhecimento escolarizado.

Para Barton (2001), a significância histórica abrange toda a "interpretação, compreensão, seleção e avaliação das situações" do passado e considera as produções subjetivas, sociais, culturais, políticas e historiográficas comunicadas de forma variada aos membros de uma sociedade.

O que permite dar significado aos acontecimentos históricos são as suas "interrelações" com outros fatos e processos do passado e do presente. A significância de um acontecimento passado se dá por uma escolha moral, pelas relações com outros eventos e sujeitos e com a interpretação da "sua importância para o presente".

Numa concepção acerca da História escolarizada, o filósofo alemão Jörn Rüsen, por sua vez, apresenta maior ênfase sobre o conceito de narrativa histórica pois, desse modo, ao contar o passado os estudantes estão fazendo uma atividade intelectual que o torna presente.

A narrativa sobre o passado, segundo Rüsen (2001), só se transforma em narrativa histórica quando tem subjacente uma interpretação deste passado nela contado. Para ele, a narrativa histórica orienta e dá sentido à vida do sujeito narrador. Nessa mesma obra, o autor afirma que o passado só tem significado como orientação na vida prática, pois pressupõe uma terminalidade, já que está em algum lugar no tempo.

Santos afirma que,

Orientar-se no tempo se relaciona com a ideia de literacia histórica de Peter Lee (2006) que significa a capacidade de ler e entender o mundo (RÜSEN, 2006). Jörn Rüsen também afirma que existe a necessidade da construção por parte do sujeito de "quadros conceituais com o qual se discute e quantifica como o passado se torna significativamente presente" (SEIXAS, 2004). Este entendimento do mundo auxilia a 
construção do significado dado ao passado, tanto por alunos quanto por professores. (SANTOS, 2013, p. 87).

No interior do espaço escolar é possível perceber a forma como determinados cânones, como a ditadura militar, têm sustentado as grandes narrativas da História nacional e universal. Presentes em manuais didáticos, em propostas curriculares e também em narrativas de professores de História, estes cânones estão contribuindo ou não para uma aprendizagem histórica emancipadora? Se for levado em conta a preocupação entre a ditadura militar e as diferentes Histórias que podem existir, como ocorre a formação da consciência histórica dos alunos e uma relação honesta e verdadeira com o passado, pois o trem da História universal, lançado vertiginosamente a um futuro desconhecido, desagrega as comunidades e faz dos seus membros seres desorientados num mundo estranho. Nem os indubitáveis progressos morais e políticos, nem a aceleração do desenvolvimento tecnológico podem ocultar o crescimento da barbárie para com as vítimas nem o desconcerto dos sobreviventes. (SCHMIDT, 2013, p. 205-206).

\section{A História Dificil dentro da escola: a ditadura civil militar}

Lidar com o passado nas aulas de História, teoricamente, deveria ser uma tarefa fácil e tranquila. No entanto, a relação que se estabelece entre os estudantes e os acontecimentos idos carece de um exercício de empatia e reflexão o que, na maioria das vezes, não acontece durante as aulas. Especificamente com relação à ditadura civil militar, tem se tornado rotineira a afirmação de que os professores apresentam uma versão de acordo com a sua perspectiva, a "História do professor". Percebe-se, dessa forma, que não há a compreensão da História enquanto uma ciência pautada em pesquisa e métodos próprios. Desse modo, uma aprendizagem histórica que busque desenvolver a consciência histórica de alunos partindo do estudo da epistemologia do conhecimento da ciência de referência deve entender que,

História é um modo distinto de pensamento, um acesso metódico para um melhor entendimento do mundo e de si, uma ferramenta para decodificar fenômenos e orientações no presente e no futuro basicamente efetuada por narrativas "verdadeiras" sobre eventos passados, mudanças e desenvolvimentos. (BORRIES, 2016, p. 171). 
Aqui, novamente, cabe resgatar a forma como a ditadura civil militar tem sido abordada nas aulas de História da Educação Básica. Considerada como um capítulo da História Difícil, esse episódio pode ser bastante conflitante e resultado de diferentes fontes e narrativas. Nesse ponto, a produção historiográfica voltada para a sala de aula parece não ter se preocupado em realizar uma discussão mais reflexiva sobre esse passado.

De modo geral, os materiais didáticos seguem a mesma linha narrativa sobre esse passado baseando-se, fundamentalmente, na descrição factual dos períodos comandados pelos cinco presidentes militares do período 1964-1985. As ações dos sujeitos, seja individual ou coletivamente, pouco são mencionadas, assim como os aspectos culturais do período.

Um exemplo disso é a utilização das músicas, como no caso das composições de Chico Buarque, presentes na maioria dos manuais didáticos, como recursos ilustrativos de uma ideia. Essas músicas, no entanto, não são utilizadas como fontes históricas que podem ser tomadas como evidências de um passado em especial, mas servem como apenas como reforço de outras ideias evidenciadas na narrativa linear do manual didático, sem relação mais ampla com o período em si e com os demais sujeitos que buscavam reagir ao que acontecia no período. Aliás, reagir a que, porque e contra quem é uma lacuna presente nas salas de aula da Educação Básica quando o assunto é a ditadura civil militar. A narrativa apresentada é linear e fechada e muitas vezes não deixa espaço para questionamentos. Os alunos questionam as diferenças entre o que estudam na escola com o que tomam conhecimento fora do ambiente escolar.

\begin{abstract}
"História" é um modo de pensamento, um acesso ao mundo e a si mesmo. Portanto pode ser aplicado e transferido para todas as partes e seções da vida. Isso tem uma consciência crucial para o ensino de História [...] Muitos indivíduos lembrarão que suas realidades historicamente relevantes foram aprendidas e introduzidas por um dramaturgo, um museu ou uma cidade, não por professores de História. (BORRIES, 2016, p. 186).
\end{abstract}

Aqui se apresenta a grande importância que a Educação Histórica dá ao verificar os conhecimentos prévios dos estudantes, pois a conviç̧ão de que os jovens conhecem elementos do passado deve ser levada em consideração. Se a ditadura civil militar é um capítulo do passado cheio de controvérsias e a História escolarizada enverga sempre para uma direção, com a o levantamento, apresentação e reconhecimento das ideias prévias dos estudantes é possível diagnosticar o que já viram e ouviram para organização do trabalho pedagógico. 
Com essas ideias levantadas, os professores de História da Educação Básica podem buscar um novo caminho no sentido de ampliar conceitos e trabalhar com novas fontes, permitindo uma narrativa que fuja do discurso tradicional.

\begin{abstract}
Partindo do pressuposto básico de que a consciência histórica é o lugar da aprendizagem, as investigações realizadas no campo da educação histórica têm tido a preocupação com questões que envolvem a definição, a conceituação, a elaboração, bem como os objetivos de investigar as funções, abordar as condições, as forças motrizes e as consequências das ideias históricas presentes na cultura escolar, seja nas ideias de professores e alunos, seja em outros elementos da cultura escolar, como os manuais didáticos. (SCHMIDT, 2013, p, 200)
\end{abstract}

Essa afirmação de que o conteúdo da ditadura civil militar é pouco reconhecido e discutido em sala de aula pode ser observada a partir dos documentos oficiais que orientam a organização curricular. Acreditando que são palavras fortemente relacionadas a esse período, foi feita a leitura da documentação oficial em busca da menção a conceitos como "ditadura", "censura", "tortura" e "morte".

Nas Diretrizes Curriculares Nacionais para a Educação Básica (BRASIL, 2013) a palavra “ditadura" é mencionada apenas uma vez na página 442, nas Diretrizes Curriculares Nacionais para a Educação Escolar Quilombola, quando afirma a importância do resgate do passado e da importância da ancestralidade africana no Brasil, antes, durante e após este período histórico. E aparece duas vezes na página 497, no singular e no plural, nas Diretrizes Nacionais para a Educação em Direitos Humanos quando faz um resgate histórico da implantação das ditaduras na América Latina, e quando afirma que o Brasil se tornou, em 1966 signatário dos pactos internacionais dos direitos civis e políticos e dos direitos econômicos e sociais. Com essa ausência, pode-se considerar que mesmo sendo um documento oficial que regula a forma como as disciplinas devem ser ministradas na Educação Básica, o conceito de ditadura não é considerado como um referencial de importância nas aulas de História.

Embora não seja o aspecto principal a ser tratado neste artigo, é importante observar que nas aulas de História da Educação Básica costuma existir uma confusão em relação a este conceito, pois muitos estudantes acreditam que ditadura é, sempre, sinônimo de ditadura militar. 
As duas vezes que a palavra "censura" é mencionada nas DCN's também está relacionada a questões de Direitos Humanos. A palavra "tortura" é mencionada quando são citadas leis contra a discriminação racial e a tortura e nas Diretrizes Nacionais para a Oferta de Educação para Jovens e Adultos em Situação de Privação de Liberdade nos Estabelecimentos Penais (BRASIL, 2013, p. 286-317). E a palavra "morte" só é citada também uma única vez na mesma Diretriz.

Os quatros conceitos - ditadura, censura, tortura e morte - também foram levantados nas Diretrizes Curriculares da Educação Básica - História, do Estado do Paraná. Fora o termo censura que foi encontrado somente quatro vezes, os outros tiveram um grande número de ocorrências no documento legal inteiro. Pode-se inferir inicialmente que no texto legal questões relacionadas a História Difícil podem ser possíveis de serem apontadas para discussão na disciplina de História. Mas os conceitos são apresentados de forma pulverizada e se encontra desde a Antiguidade até o século XXI. O conceito que mais aparece é o de tortura, em sua grande maioria temporalmente relacionado ao período da inquisição e ao da escravidão africana no Brasil. Poucas são as referências aos quatro termos quando se trata de História recente do Brasil. Isto também traz questões importantes para a discussão acerca da importância dos debates sobre o passado para o ensino e aprendizagem de história a partir de questões sobre a História Difícil.

A coleção didática no componente curricular História mais escolhida e distribuída pelo PNLD 2017 foi o de autoria de Alfredo Boulos Junior, "História, Sociedade e Cidadania" no Ensino Fundamental, da editora FTD, que teve um total de 3.387 .161 de exemplares distribuídos em escolas de todo o território nacional.

Somente no nono ano é que conteúdos de história recente são apresentados. Cabe lembrar que, apesar de pretender ser um material de caráter temático, ele o conteúdo deste livro abrange história geral e história do Brasil desde o final do século XIX até meados da segunda década do século XXI, com questões de globalização e do governo Dilma Roussef.

Mesmo tendo um capítulo de quase trinta páginas exclusivamente tratando do período da ditadura civil militar brasileira, ele é intitulado "regime militar" e está inserido dentro de uma unidade intitulada "Movimentos Sociais", o que pode trazer alguns problemas de interpretação do aluno, pois traz tanto os conteúdos da História geral quanto da História do Brasil de forma linear dentro de um título que remete a uma organização social. Isso pode não auxiliar a construção de uma narrativa sobre o passado que faça com que a linearidade seja superada e a criticidade seja buscada no processo de ensino-aprendizagem.

O pesquisador Bodo von Borries $(2016,179)$ afirma que "Uma história é escrita ou contada de um ponto de vista de uma comunidade específica e de uma identidade de determinada comunidade, o que denomina de "concretude da identidade". 


\section{Considerações finais}

Questiona-se a forma como a documentação legal, que ampara a construção de currículos que orientam práticas escolares e estruturam materiais didáticos, apresenta períodos difíceis do nosso passado recente. Desse modo, a escola e, mais especificamente, como o professor de História pode desenvolver um trabalho de discussão histórica em sala de aula que leve em conta o enfrentamento de questões que tragam à tona aspectos difíceis e controversos do passado.

Desta forma, pode-se concluir que existe uma necessidade muito grande de que haja uma discussão para que se repense a forma como a ditadura civil militar brasileira está sendo trabalhada e está sendo trazida para a escola e inserida no trabalho pedagógico. Os estudos apresentados e o modo como está posto nos documentos oficiais não conseguem contemplar as dimensões que abarcam as amplas perspectivas de passado aos quais os alunos têm acesso e que auxiliam a construir uma visão de passado, que muitas vezes contradizem o que está presente nos documentos legais e nos livros didáticos, pois os estudantes não chegam as escolas como tábulas rasas, eles tem contato com variadas formas de narrativas sobre o passado, como afirmam pesquisadores como Barton (2001) e Seixas (1998).

No momento em que os professores sofrem ataques recorrentes e que veem sua autoridade e conhecimento acadêmico e profissional serem questionados diariamente por projetos de cerceamento de discussão e políticas de desmobilização da carreira docente, é necessário que o seu conhecimento teórico e epistemológico sobre o passado não seja desmerecido e que as discussões sobre a História Difícil possam ser levadas para dentro de sala de aula e auxiliem os alunos a construir narrativas sobre a ditadura civil militar brasileira que superem o passado cor de rosa ou onde os alunos possam perceber que os sujeitos históricos deste período sofreram e ainda sofrem as consequências deste período recente da nossa História. É necessário que os documentos oficiais e também os livros didáticos incorporem os debates sobre este período controverso da História do Brasil e que traga para a sala de aula fontes históricas que mostrem as diversas faces deste período para que seja dado ao aluno a possibilidade de construir uma relação com este passado de forma mais honesta e verdadeira possível.

E ao construir narrativas sobre o período da ditadura civil militar brasileira e as relações controversas entre os sujeitos que a vivenciaram, os alunos utilizem fontes variadas e as relacionem de modo a perceber que o passado pode ser resgatado de variadas maneiras e que o esforço de construção de uma narrativa histórica sobre este período passa por uma discussão profunda e verdadeira sobre este período difícil da História brasileira entendendo 
no fim que, como afirma Bodo von Borries, as "melhores" Histórias podem se revelar desconfortáveis (BORRIES, 2016).

\section{Referências}

BARTON, Keith. Explicações da significância histórica em alunos do Ensino Básico. O Estudo da História, n. 4, p. 207-236, 2001.

BRASIL. Constituição da República Federativa do Brasil de 1988. Brasília. Disponível em: http://www.planalto.gov.br/ccivil 03/constituicao/constituicao.htm. Acesso em $25 \mathrm{de}$ setembro de 2018.

BRASIL. Lei 9.394, de 20 de dezembro de 1996. Estabelece as Diretrizes e Bases da Educação Nacional. Rio de Janeiro: DP\&A, 2002.

CAINELLI, Marlene; SCHMIDT, Maria Auxiliadora (Orgs.). Educação História: teoria e pesquisa. Ijui, RS: Editora UNIJUI, 2011.

CASTEX, Lilian Costa. O Conceito Substantivo Ditadura Militar Brasileira (1964-1984) na Perspectiva de Jovens Brasileiros: Um Estudo de Caso dm Escolas de Curitiba - PR. 2008. 186 f. Dissertação (Mestrado em Educação) Universidade Federal do Paraná, Curitiba, 2008.

CHAGAS, Valnir. Núcleo Comum para os Currículos do Ensino de $1^{\circ}$ e $2^{\circ}$ Graus. Revista brasileira de Estudos pedagógicos. Brasília, v.74, n. 177, p.385- 423, maio/ago. 1993.

CHAVES, Fátima Rosário Costa. A significância de personagens históricas na perspectiva de alunos portugueses e brasileiros. 2006. 133 f. Dissertação (Mestrado em Ciências da Educação - Supervisão Pedagógica em Ensino de História) - Instituto de Educação e Psicologia, Universidade do Minho, Braga, 2006.

FONSECA, S. G. Caminhos da história ensinada. Campinas: Papirus. 1995.

FONSECA, S. G. Didática e prática de ensino de história: experiências, reflexões e aprendizados. Campinas, SP: Papirus, 2003.

GERMINARI, Geyso Dongley; GONÇALVES, Rita de Cássia. As políticas educacionais e formação do professor de História no Brasil: desafios contemporâneos. Interacções. Lisboa, v. 12, n. 40, p. 55-69, 2016. 
LEE, Peter. Em direção a um conceito de literacia histórica: a escolha de recursos na aula de História. Educar em Revista, Curitiba, n. 164, p. 131-150, 2006. Edição especial.

NEVES, Joana. O ensino de História nos 50 anos do Golpe Militar - Estudos Sociais sob a ditadura. P. 13-40. In: SCHMIDT, Maria A.; ABUD, Kátia. 50 anos da Ditadura Militar: Capítulos sobre o ensino de História no Brasil. Curitiba: WA, 2014.

OLIVEIRA, Jackes Alves de. Educação Histórica e Aprendizagem da "História Dificil" em Vídeos do Youtube. 2016. 120 f. Dissertação (Mestrado em Educação). Universidade Federal do Paraná, Curitiba, 2016.

PARANÁ. Diretrizes Curriculares da Educação Básica - História. Curitiba: SEED, 2008.

PARANÁ. Secretaria de Estado da Educação. Diretrizes curriculares da educação do campo. Curitiba: SEED, 2006.

PARANÁ. Currículo Básico para a Escola Pública do Estado do Paraná. Curitiba: SEED, 1990.

RUSEN, Jörn. Aprendizagem histórica: fundamentos e paradigmas. Curitiba: W. A. Editores, 2012.

RÜSEN, Jörn. O livro didático ideal. In: SCHMIDT, Maria Auxiliadora; Barca, Isabel; MARTINS, Estevão de Rezende. Jörn Rüsen e o ensino de História. Curitiba: Ed. UFPR, 2010. p. 109-128.

RÜSEN, Jörn. Experiência, interpretação, orientação: três dimensões da aprendizagem história. In: SCHMIDT, Maria Auxiliadora Moreira dos Santos; BARCA, Isabel; MARTINS, Estevão de Resende. Jörn Rüsen e o ensino de história. Curitiba: Ed. UFPR, 2010a. p. 79-91.

RÜSEN, Jörn. O livro didático ideal. In: SCHMIDT, Maria Auxiliadora Moreira dos Santos, BARCA, Isabel; MARTINS, Estevão de Resende. Jörn Rüsen e o ensino de história. Curitiba: Ed. UFPR, 2010b. p. 109-127.

RÜSEN, Jörn. História Viva: formas e funções do conhecimento histórico. Brasília: UNB, 2007a.

RÜSEN, Jörn Reconstrução do Conhecimento Histórico: os princípios da pesquisa histórica. Brasília: UNB, 2007b.

RÜSEN, Jörn. Razão histórica: teoria da História, fundamentos da ciência histórica. Brasília: UNB, 2001. 
SANTOS, Rita de Cássia Gonçalves Pacheco dos. A significância do passado para professores de história. 2013. 262 p. Tese. (Doutorado em Educação) - Universidade Federal do Paraná, Curitiba, 2013.

SCHMIDT, Maria Auxiliadora -Aprendizagem da "burdeing history": desafios para a educação histórica. Revista de Humanidades. Caicó, v.16, n. 36, p.10-26, jan./jul. 2015. Dossiê Ensino de História. Disponível em http: //www.periodicos.ufrn.br/mneme/article/viewFile/8094/6124.

SCHMDT, Maria Auxiliadora Os sentidos conferidos ao agir e os desafios para a aprendizagem e formação da consciência histórica de jovens alunos. Revista Documento/Monumento. Dossiê: História regional, Historiografia e Ensino de História. Cuiabá, UFMT, v. 9, n. 1, p. 107-206, out/2013.

SCHMIDT, Maria A. M. O significado do passado na aprendizagem e na formação da consciência histórica de jovens alunos. In: CAINELLI, M.; SCHMIDT, M. A. (Org.). Educação Histórica: Teoria e pesquisa. Ijuí: Ed. Unijuí, 2011.

SCHMIDT, Maria Auxiliadora M. S. Cognição histórica situada: que aprendizagem História é está? In: SCHMIDT, Maria Auxiliadora; BARCA, Isabel (orgs). Aprender História: perspectivas da Educação Histórica. Ijuí: Unijuí, 2009. p. 22-47.

SCHMIDT, M. A.; GARCIA, T. M. B. Consciência histórica e crítica em aulas de História. Fortaleza: Secretaria da Cultura do Estado do Ceará/Museu do Ceará, 2006.

SEIXAS, Peter. Scheweigen! Die Kinder! or, Does Postmodern History Have a Place in the Schools?. In: STEARNS, Peter N.; SEIXAS, Peter; WINEBURG, Sam (eds.). Knowing, teaching and learning History: national and international perspectives. New York: New York University Press, 2000. 482 p. p. 19-37.

SEIXAS, Peter. Conceptualizing the Growth of Historical Understanding. In: OLSON, D.R.; Torrence, N. The Handbook of Education and Human Development. London: Blackwell, 1998. 816 p. p. 765-783.

SEIXAS, Peter. Conceptualizing the Growth of Historical Understanding. In: OLSON, D. R.; TORRENCE, N. The Handbook of Education and Human Development. London: Blackwell, 1998b. 816 p. p. $765-783$.

TRINDADE, Judite Maria Barbosa. A História sumiu: o ensino de Estudos Sociais durante a Ditadura Militar. In: SCHMIDT, Maria A.; ABUD, Kátia. 50 anos da Ditadura Militar: Capítulos sobre o ensino de História no Brasil. Curitiba: WA, 2014. 


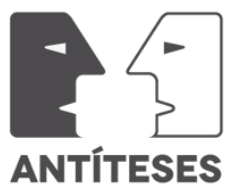

VON BORRIES, Bodo. Coping with burdening history. In: BJERG, H.; LENZ, C.; THORSTENSEN, E. (eds.). Historicizing the Uses of the Past. Scandinavian Perspectives on History Culture, Historical Consciousness and Didatics of History Related to Word War II. Bielefeld: Transcript - Verlag für Kommunikation, Kultur und soziale Praxis, 2011.

VON BORRIES, Bodo. Jovens e consciência histórica. SCHMIDT, Maria Auxiliadora; FRONZA, Marcelo; NECHI, Lucas Pydd. (org. e trad.) Curitiba: W. A. Editores, 2016.

Recebido em 31/10/2018

Aprovado em 09/01/2019 